\title{
Effects of pre-stimulus processing on subsequent events in a warned Go/NoGo paradigm: Response preparation, execution and inhibition
}

\author{
Janette L. Smith, Stuart J. Johnstone* and Robert J. Barry \\ Department of Psychology and Brain \& Behaviour Research Institute, University of \\ Wollongong, Australia.
}

****Note to type-setter: "Brain \& Behaviour Research Institute" is a registered name and should not be changed in any way.****

*Corresponding author: S. J. Johnstone, Dept. of Psychology, University of Wollongong, Northfields Avenue, Wollongong NSW 2522, Australia.

Tel.: +612 4221 4495; Fax: +6124221 4163

Email address: stuart_johnstone@uow.edu.au 


\begin{abstract}
The cued Go/NoGo task elicits response preparation during the foreperiod, and, depending on the S2 signal, either response execution or inhibition. This study aimed to determine how processes in the foreperiod might affect or predict post-S2 processing. Thirty-two adults participated in a cued Go/NoGo task (50\% Go), with a median split of mean RT producing "Fast" and "Slow" groups. ERP measures were subjected to both ANOVA and regression techniques. There were no differences in the N2 NoGo effect related to response speed, nor was the effect related to pre-S2 processes. The anterior shift of the NoGo P3 was larger in the Fast group, and while the late $\mathrm{CNV}$ was associated with the absolute amplitude of both Go and NoGo P3, it was not related to the anterior-posterior Go/NoGo differences.

Together, these data suggest that the inhibitory process may be reflected in the NoGo P3 effect, rather than the NoGo N2 effect.
\end{abstract}

Keywords: Contingent negative variation; inhibition; N2; P3; reaction time. 


\section{Introduction}

The preparation of a motor response, and the subsequent execution or inhibition of that response, has been studied frequently using cued reaction time tasks. In these investigations, researchers tend to focus on preparatory processing in the foreperiod, without considering the events following the imperative signal (with the exception of reaction time), or on the execution vs. inhibition of a response, without considering possible differences in response preparation that may affect both responding and inhibiting. Research is needed that examines the link between preparation and execution/inhibition of a motor response in the same set of participants, and considers not only processes in the foreperiod, but also their effects on subsequent processing after the imperative signal. In this paper, we examine which components in the foreperiod of a cued-Go/NoGo task contribute to reaction time, as well as to inhibitory differences between subjects.

In a foreperiod paradigm, where one stimulus (S1) cues the participant for the presentation of another (S2), a negative wave arises during the cue-target interval, termed the Contingent Negative Variation (CNV; Walter et al., 1964). The scalp-recorded CNV is thought to be the sum of several separate negative waves, the early $C N V$ (peaking between 450 and $650 \mathrm{~ms}$ post-S2, and linked to orienting by Loveless, 1979), the stimulus-preceding negativity (peaking toward the end of the foreperiod, and linked to stimulus anticipation by Damen \& Brunia, 1987), and the readiness potential (a slow-rising negativity peaking just before a planned voluntary response is executed, discovered by Kornhuber \& Deecke, 1964). In most S1-S2 paradigms requiring a response to $\mathrm{S} 2$, these two late waves cannot be distinguished. Thus, we refer to the composite of both these waves as 'late CNV', but because a motoric response task was used in this study, we interpret the late CNV as a reflection primarily of response preparation processes.

There has been much previous research into the relationship of the late CNV with RT, and although generally a large amplitude late $\mathrm{CNV}$ is associated with fast RT (e.g., Hillyard \& Galambos, 1967; Rebert \& Sperry, 1973; Papakostopoulos \& Fenelon, 1975; Brunia \& 
Vingerhoets, 1980; Haagh \& Brunia, 1985; Wascher et al., 1996), some researchers have suggested that the relationship is rather weak (e.g., Lombroso, 1969; Peters et al., 1970; Näätänen \& Gaillard, 1974; Irwin et al., 1966; Connor \& Lang, 1969). In a summary of the literature, Rebert and Tecce (1973) indicated that, on average, only 13\% of the variability in RT could be accounted for by variability in the late CNV. Rebert and Tecce noted that individual differences other than the processes reflected by the late $\mathrm{CNV}$, and other situational variables, might also influence motor responses. Reaction time could depend on any other process reflected in the ERP to the warning stimulus, such as the degree of orienting of attention to S1, indexed by the early CNV, and the N1 and P2 components relating to the sensory processing of the warning signal. Previous reports suggest larger early $\mathrm{CNV}$ is related to faster reaction times, whether using correlational techniques (Gaillard, 1976), within-subject comparisons of fast vs. slow trials (Haagh \& Brunia, 1985), or between-subjects analyses (Connor \& Lang, 1969). However, the within-subject relationships between RT and both N1 and P2 to the warning stimulus do not appear significant (Hillyard, 1969; Waszak \& Obrist, 1969; Näätänen \& Gaillard, 1974; Haagh \& Brunia, 1985). Hence, one aim of the present study was to investigate the relationship between reaction time and components of the ERP during the foreperiod, both in discrete analyses (via a median split of participants' mean R'T to create groups of Fast and Slow responders) and using multiple regression.

In a typical Go/NoGo task, several robust ERP component differences occur between stimulus types, including an augmented N2 component for NoGo relative to Go stimuli, particularly at frontocentral sites (Fallgatter \& Strik, 1999; Filipovic et al., 1999; Jodo \& Kayama, 1992; Bekker et al., 2004; Bruin \& Wijers, 2002; Filipovic et al., 2000; Nieuwenhuis et al., 2003; Wang et al., 2002; Oddy et al., 2005). Also apparent is a more anterior focus for the NoGo P3, such that at frontal and central sites, P3 is larger for NoGo than Go stimuli (e.g., Simson et al., 1977; Pfefferbaum et al., 1985; Pfefferbaum \& Ford, 1988; De Jong et al., 1990; Eimer, 1993; Roberts et al., 1994; Falkenstein et al., 1999; Fallgatter \& Strik, 1999; Filipovic et al., 1999; Tekok-Kilic et al., 2001; van Boxtel et al., 2001; Falkenstein et al., 2002; Oddy et al., 2005). Thus, there appears to be robust evidence linking N2 and P3 to inhibitory processes. However, debate is ongoing as to the interpretation of results from these studies, as well as those using other inhibitory tasks such as the stop-signal task (e.g., Kok et al., 
2004; Ramautar et al., 2004) and the Eriksen flanker task (e.g., Kopp et al., 1996a; Kopp et al., 1996b; Heil et al., 2000).

It seems reasonable to expect that the execution and inhibition of responses in the Go/NoGo task would also differ between groups of Fast and Slow responders. The notion of a speed-accuracy trade-off comes into play, such that, when responses are fast, commission errors are particularly likely, and if the participant is to inhibit their response, presumably the strength of inhibition must increase. Thus, if responses are fast on average, inhibition must be stronger in order to overcome the fast Go response, resulting in a larger N2 NoGo effect in the Fast group. Support for this notion comes from Jodo and Kayama (1992), who required that one group of subjects respond within $300 \mathrm{~ms}$ of the Go signal, and another group to respond within $500 \mathrm{~ms}$, and found subsequent N2 effects suggesting inhibition was stronger for the fast responders. Unfortunately, however, they did not report behavioural results for inhibitory performance. Similarly, Band et al. (2003) instructed participants to focus either on both response speed and accuracy, or on speed at the expense of accuracy. Under speed compared to balanced instructions, responses were faster to the Go stimulus, but marginally more commission errors were made. Their N2 results also suggested that inhibition on NoGo trials was stronger when fast responses were given. In addition to effects on the $\mathrm{N} 2$ component, a response process which is relatively fast on average may also affect the P3 component, yet neither Jodo and Kayama (1992) nor Band et al. (2003) considered the P3. Hence one aim of this study was to examine differences in inhibitory components between Fast and Slow responders.

Given that we aim to determine whether group differences in warning ERP components exist, and that we expect group differences in post-S2 inhibitory processes, it may be valuable to consider how processes occurring before S2 might affect processing after S2. Using multiple regression techniques, we will examine how pre-S2 variables might be associated with response execution and inhibition processes to Go and NoGo stimuli. 


\section{Method}

\section{Participants}

Thirty-two adults (17 males) aged between 18 and 41 years (mean 24.1 years) participated to meet part of an undergraduate course requirement. To be included in the study participants had to show no signs of neurological disorders, score above 80 on the Standard Progressive Matrices (SPM) test (a paper and pencil test of general cognitive functioning; Raven, 2000), have had no caffeine in the two hours prior to testing, and no alcohol in the past 24 hours. In addition, participants had not taken illicit drugs in the 24 hours prior to testing, or more than once a month for the past 6 months. All but 5 participants were right-handed. The research protocol was approved by the joint University of Wollongong and Illawarra Area Health Service Human Research Ethics Committee.

\section{Stimuli}

Participants completed a Go/NoGo task in which a warning tone $(1500 \mathrm{~Hz})$ was followed $1500 \mathrm{~ms}$ later by either a $1000 \mathrm{~Hz}$ tone, to which the subject had to press a button, or a 2000 $\mathrm{Hz}$ tone, which required the subject to withhold their response. There was a variable interval (3.0-4.0 s, $3.5 \mathrm{~s}$ mean) until the next warning stimulus. Fifty percent of trials were Go trials, and the order of Go and NoGo stimuli was randomised. All stimuli were binaurally presented through headphones at $70 \mathrm{~dB}$ SPL and lasted $200 \mathrm{~ms}$ (40 ms rise and fall time). Eight practice trials were presented, followed by an experimental set of two blocks of 30 trials each. Subjects were instructed that the warning stimulus cued them for the second stimulus, and that they were to press as quickly as possible only to the Go stimulus. All subjects responded with their right index finger.

\section{Procedure}

Participants were familiarised with the testing procedure and laboratory before written informed consent was obtained, then filled out a brief questionnaire assessing for neurological disorders, drug use, etc., before completing the SPM. 
Once recording electrodes were fitted, subjects were seated in a sound-attenuated, electrically shielded booth where testing took place. Instructions for the task appeared on a computer screen for the subject to read. Subjects were encouraged to keep as still as possible throughout the task and to keep eye movements to a minimum using a central fixation cross on the computer monitor. After the practice block, any problems with understanding the instructions were corrected, and a check for tone differentiation was performed. Subjects then completed the experimental blocks, with a short break between blocks if necessary.

\section{Electrophysiological recording}

An electrode cap containing tin electrodes was fitted, with continuous EEG recording from 17 sites (Fp1, Fp2, F7, F3, Fz, F4, F8, T3, C3, Cz, C4, T4, T5, P3, Pz, P4, and T6) of the International 10-20 system, referenced to linked earlobes. Vertical electrooculogram (EOG) was obtained with tin cup electrodes placed $1 \mathrm{~cm}$ above and below the left eye, and horizontal EOG from electrodes $1 \mathrm{~cm}$ lateral to the outer canthi. Impedances for ear and eye electrodes were below $3 \mathrm{k} \Omega$, with scalp electrodes below $5 \mathrm{k} \Omega$. The subject was grounded by a cap electrode located midway between Fpz and Fz. EEG and EOG signals were amplified 5,000 times with a bandpass down $3 \mathrm{~dB}$ at 0.01 and $100 \mathrm{~Hz}$, via 24 channels of Grass amplifiers, sampled through an A/D card at $512 \mathrm{~Hz}$, and displayed and recorded using Neuroscan software.

\section{Data extraction}

The ERP epoch began $100 \mathrm{~ms}$ before the warning stimulus and lasted until $900 \mathrm{~ms}$ after the Go/NoGo stimulus (total $2500 \mathrm{~ms}$ ). Epochs were baselined to the pre-warning activity, and digitally low-pass filtered down $48 \mathrm{~dB}$ at $15 \mathrm{~Hz}$. Epochs were rejected if subjects made an (incorrect) response to the warning or NoGo stimuli, or made no response to the Go stimulus (omission error). Epochs were also rejected if amplitude exceeded $\pm 100 \mu \mathrm{V}$ in any EOG channel, or $\pm 150 \mu \mathrm{V}$ at any scalp site. Average ERPs were calculated for both Go and NoGo stimuli separately. 
In order to establish latency ranges over which the early and late CNV were maximal, and the contribution of other components to the waveforms were minimal, ERPs were reduced to 136 points via a spline fit and subjected to a principal components analysis (PCA). The PCA used the covariance matrix and varimax rotation (Kayser \& Tenke, 2003), and extracted 11 factors together accounting for $88.92 \%$ of variance (see Figure 1). This plot demonstrates the orthogonal nature of the components used in these analyses. The first two factors extracted represented the late CNV (54.0\% of variance) and the early CNV $(11.5 \%)$. Several other factors were also extracted, representing the early stimulus processing components of the ERPs. The PCA-defined factors were used only to define independent time ranges over which mean amplitude measures were derived. These were, for the late $\mathrm{CNV}$, the last $650 \mathrm{~ms}$ before the onset of S2, and for the early CNV, 350-700 ms post-S1. In addition to this, several peaks were quantified, which were S1-N1, S1-P2, S2-N2, S2-P3. A computer algorithm selected the maximum (positive components) or minimum (negative components) within a fixed latency range at a specified site, and then amplitude measurements were performed at the same latency at all other scalp sites (as recommended by Picton et al., 2000). Search parameters for each peak, as well as latency means, are shown in Table 1.

Insert Figure 1, Table 1 about here

\section{Data analysis}

Behavioural data analysed were the proportion of correct responses to the warning, Go and NoGo stimuli, and mean reaction time to Go stimuli. Those participants whose mean RT was faster than the median were placed in the "Fast responders" group, and those who were slower than the median were placed in the "Slow responders" group (Wascher et al., 1996). While we recognise that using a median split in a normal distribution is not ideal, it is an economical use of available data rather than excluding participants near the median to create more distinct groups. Figure 2 shows the distribution of mean RT for each group. Group differences in behavioural data and SPM scores were assessed using ANOVA.

\section{Insert Figure 2 about here}


In order to assess whether group differences in RT might be due to differences in sensitivity (d') and response bias (the natural $\log$ of $\beta$ ), an analysis of these measures was undertaken using the method outlined by Macmillan and Creelman (1991). Where hit and false alarm rates were equal to 1 or 0, respectively, the procedure of Macmillan and Kaplan (1985) was followed: 1 was replaced with $1-1 /(2 \mathrm{~N})$, and 0 was replaced with $1 /(2 \mathrm{~N})$, where $\mathrm{N}=30$, the number of Go and NoGo trials. Group differences in these measures were assessed using ANOVA.

The original measurements of post-S2 components were peak-to-baseline, relative to the 100 ms period preceding S1. However, in line with previous Go/NoGo research, we rebaselined these measurements to a $100 \mathrm{~ms}$ pre-S2 baseline, by calculating the mean amplitude over this period for each subject, stimulus type and scalp site, and subtracting this from the post-S2 measurements. This $100 \mathrm{~ms}$ pre-S2 baseline correlated with the late $\mathrm{CNV}$ mean amplitude measure at all sites $r>.83$ (mean, using Fisher's z-transformations $=.935$ ); therefore the post-S2 ERPs are effectively equated for prior preparatory activity. Thus, components in the foreperiod were measured relative to a $100 \mathrm{~ms}$ pre-S1 baseline, while post-S2 components were measured relative to a $100 \mathrm{~ms}$ pre-S2 baseline.

Analyses of ERP components were restricted to the sites F3, Fz, F4, C3, Cz, C4, P3, Pz and P4, in a 3 x 3 (lateral x sagittal) matrix. The mean of Go and NoGo values were used, since participants could not predict which stimulus type would be presented. Peak and mean amplitude measures were subjected to a Lateral (left/midline/right) x Sagittal (frontal/central/parietal) x Group (Fast/Slow) repeated-measures MANOVA. For post-S2 components, a Lateral x Sagittal x Group x Type (Go/NoGo) structure was used. Planned contrasts for the Lateral factor compared the left with the right hemisphere, and the mean of these with the midline, and for the Sagittal factor compared frontal with parietal activation, and the mean of these with central activation. Such contrasts are optimal for deriving information about the topographic distributions of each component. As the contrasts were planned and there were no more of them than the degrees of freedom for effect, no Bonferroni-type adjustment to alpha was necessary (Tabachnick \& Fidell, 1996). Where there were main effects of Type or Group, ERP data were also submitted to vector scaling 
(McCarthy \& Wood, 1985) and only condition x topography interactions that remained significant after this procedure are reported. All contrasts reported have $(1,30)$ degrees of freedom.

In addition to the repeated-measures analyses, regression of reaction time, N2 and P3 measures were also performed, using six pre-S2 predictors. The predictor variables selected were the peak amplitude and latency of S1-N1 at Fz, peak amplitude and latency of S1-P2 at $\mathrm{Pz}$, mean amplitude of early $\mathrm{CNV}$ at $\mathrm{Fz}$, and the mean amplitude of late $\mathrm{CNV}$ at $\mathrm{Cz}$. These sites were chosen as they were the site of maximum amplitude for their respective components.

Standard multiple regressions were performed, assessing the multiple correlation coefficient $\mathrm{R}$ (the correlation between the actual values of the dependent variable, and those predicted by the regression equation), $\mathrm{R}^{2}$ (the proportion of variation in the dependent variable which is predictable from the linear combination of scores on the predictor variables), Adjusted $\mathrm{R}^{2}$ (which adjusts the proportion explained for the sample size), the significance of $\mathrm{R}$ (null hypothesis $\mathrm{R}=0$ ), and the standardised and unstandardised coefficients (and significance tests on these). In addition, the unique contraction of significant predictors, in terms of the variance accounted for, was also assessed (Tabachnick \& Fidell, 1996).

\section{Results}

\section{Behavioural performance}

Table 2 shows group means on behavioural and participant measures. The groups were equivalent on age and cognitive functioning (SPM standardised score), but differed significantly on RT, as expected from the grouping criterion, as well as on within-subject variability in R'T (Go R'T SD). Performance (percentage correct) was above 96\% for each stimulus type and group, and performance was slightly better for Go than NoGo stimuli, more so in the Fast than Slow group, although no group differences were significant. Sensitivity and bias were also not significantly different between groups. 
Insert Table 2 about here

\section{Mean and peak amplitudes}

Grand mean ERP waveforms for each group across the whole epoch (100 pre-S1 to $900 \mathrm{~ms}$ post-S2, relative to a pre-S2 baseline), averaged across stimulus type, are seen in Figure 3. Clear peaks are visible for the S1-N1 and S1-P2 peaks, and it appears that the S1-N1 is larger in the Slow group, while the S1-P2 component appears larger in the Fast group. The Early CNV is apparent following S1-P2 as a frontal negativity beginning approximately 300-700 ms post-S1. The late CNV arises towards the end of the foreperiod, appearing centrally maximal and larger in the Fast group.

\section{Insert Figure 3 about here}

Grand mean ERPs to Go and NoGo stimuli can be seen in Figure 4(a) for the Fast group, and Figure 4(b) for the Slow group. A frontocentral S2-N1 component is visible approximately $100 \mathrm{~ms}$ post-S2, followed by an enhanced frontal negativity on NoGo trials around $200 \mathrm{~ms}$ post-S2. This NoGo N2 peak is much clearer in individual subject waveforms than in the grand mean, due to its latency jitter. The S2-P3 component follows, peaking around $300 \mathrm{~ms}$ post-stimulus, and it appears parietally maximal following Go stimuli, but centrally maximal following NoGo stimuli. That is, the P3 appears larger for NoGo than Go at frontocentral but not parietal sites. Also, this effect appears larger in the Fast group.

\section{Insert Figure $4 a, b$ about here}

Effect summaries for warning ERP amplitudes are presented in Table 3, along with means. Due to limited space, we do not describe or discuss the topographic results unrelated to Group which appear in Table 3 for the S1-N1, S1-P2 and Early CNV components. The latency of S1-N1 at Fz was 114.6 ms, and there was no group difference in S1-N1 latency 
$($ Fast $=112.5 \mathrm{~ms}$, Slow $=116.7 \mathrm{~ms}, \mathrm{~F}<1)$. Across the scalp, the S1-N1 was larger in the Slow group, but the topography did not differ between groups.

\section{Insert Table 3 about here}

The S1-P2 peaked at Pz at $231.4 \mathrm{~ms}$, with no group difference in latency (Fast $=235.2 \mathrm{~ms}$; Slow $=227.6 \mathrm{~ms}, \mathrm{~F}<1$ ). The Slow group showed a left $>$ right effect, while the Fast group showed a reversed and reduced hemispheric difference. For both groups, these hemispheric effects were larger centrally than frontally and parietally.

The topography of the early CNV tended to differ between groups, with the Fast responders showing a greater frontal midline $>$ hemispheres effect than the Slow group. However, this topographic difference only approached significance.

The late CNV showed a frontocentral maximum, with a midline $>$ hemispheres effect. Centrally, there was a left midline maximum (both left $>$ right, and midline $>$ hemispheres), while frontally and parietally the laterality effect was reduced. Across the scalp, there was a tendency for Fast responders to have a larger late CNV than Slow responders. While the groups had a similar midline $>$ hemispheres effect parietally, frontally there was a much larger effect in the Fast group, while the Slow group had almost no effect.

The S2-N2 peaked at Fz at 201.7 ms. There were no significant effects of Type or Group on S2-N2 latency. The S2-N2 showed a frontal hemispheric maximum (see Table 4). Across the scalp, S2-N2 amplitude tended to be larger to NoGo than Go stimuli. The difference between stimulus types was largest frontally and smallest centrally. For Go stimuli, there was a left $>$ right effect, while this effect was reversed for NoGo stimuli. The Fast group showed a strong central $<$ frontal and parietal effect which was reversed and reduced in the Slow responders. There were no significant Type x Group interactions for S2-N2 amplitude ${ }^{1}$. 
The S2-P3 peaked at $\mathrm{Pz}$ at $344.3 \mathrm{~ms}$, and was parietocentral and right midline maximal. The right $>$ left effect was larger centrally than frontally and parietally, and the midline > hemispheres effect was largest parietocentrally. P3 amplitude was larger for NoGo than Go at frontal and central but not parietal sites. In addition, while the right $>$ left effect was reduced for NoGo relative to Go stimuli, the midline $>$ hemispheres effect was increased.

Across the scalp, the Fast responders showed a larger S2-P3 than Slow responders, with the difference largest centrally. The Slow group exhibited a smaller frontal NoGo P3 augmentation than the Fast group. The Type x Lateral x Sagittal x Group interaction revealed that while both groups showed the same midline $>$ hemispheres effect for both stimuli at parietal sites, the Fast group showed a large NoGo $>$ Go effect, particularly in the midline, and the Slow group displayed a very small NoGo $>$ Go effect, with little midline $>$ hemispheres difference. There were no significant main effects or interactions for S2-P3 latency.

\section{Multiple regression}

Table 5 shows the full correlation between all predictor variables used in the regressions, while Table 6 shows the regression coefficients and tests of significance. The regression for mean RT approached significance. Late CNV at $\mathrm{Cz}$ accounted for $13.7 \%$ of variability in RT, while S1-P2 latency contributed $9.7 \%$. Fast mean RT was related to a large late CNV and a later S1-P2 peak.

\section{Insert Table 5 about here}

The S2-N2 measure chosen for regression was the amplitude difference (Go - NoGo) at Fz, where large positive difference scores reflect a larger inhibitory N2 effect. The difference between types at this site was statistically significant (paired $\mathrm{t}[31]=3.8, \mathrm{p}=.001$ ). The overall regression was not significant, but individually, the late and early CNV measures contributed to variability in the difference score (accounting for $14.4 \%$ and $13.5 \%$ of the 
variance, respectively). In addition, we also performed separate regressions on the raw amplitude of the NoGo N2 and Go N2 at Fz, neither of which reached significance.

For the S2-P3, the difference in anterior-posterior gradient between Go and NoGo types $(\mathrm{NoGo}(\mathrm{Pz}-\mathrm{Fz})-\mathrm{Go}(\mathrm{Pz}-\mathrm{Fz}))$ was chosen, since it retained the important topographic type differences found in the ANOVA. However, regression on this measure did not reach significance, with no significant predictor variables.

In order to examine some of the crucial S2-P3 differences between groups and types, we performed a regression on the absolute amplitude of the Go S2-P3 at Pz and the NoGo S2P3 averaged across $\mathrm{Fz}$ and $\mathrm{Cz}$ (because the NoGo $>$ Go P3 effect is greatest frontocentrally). For Go S2-P3 at Pz, the regression was significant, but no individual predictor variables reached significance. Late CNV uniquely accounted for $9.6 \%$ of the variance, and S1-P2 at Pz for $9.5 \%$.

For the NoGo S2-P3 averaged across $\mathrm{Fz}$ and $\mathrm{Cz}$, the regression was significant. Two predictors reached significance; the late $\mathrm{CNV}$ at $\mathrm{Cz}$ accounted for $41.5 \%$, and S1-P2 latency accounted for $12.2 \%$ of the variance. In addition, two other variables approached significance: S1-N1 latency accounted for $6.9 \%$, and the early CNV at Fz accounted for 6.3 $\%$ of the variance.

\section{Discussion}

This study was designed to examine whether components in the foreperiod of a warnedGo/NoGo task, as well as components related to response execution and inhibition, differed in terms of participants' mean speed of response. We also aimed to determine whether mean RT and changes in inhibitory processes could be predicted from these pre-S2 components, in particular the late $\mathrm{CNV}$, an index of response preparation. 
Several group differences in the ERP components to the warning stimulus were apparent. Initially, the S1-N1 and early CNV results seem surprising, since a large N1 has been linked to more attentive processing of a stimulus (Näätänen \& Picton, 1987), and the early CNV is thought to be an index of the orienting response (e.g., Loveless, 1979). The current results seem to suggest that the Slow group paid more attention to the warning stimulus, contrary to expectations. The P2 results, however, may help to explain this surprising outcome. Studies by Oades (1998) and Hegerl and Juckel (1993) have shown that P2 amplitude is related to the suppression of irrelevant activity/processing. The central decrease in S1-P2 for the Slow group may reflect less of this suppression of irrelevant activity. Together, the results suggest greater attention was paid to the warning stimulus by the Slow than Fast group, which was suppressed to a greater extent in the Fast group at the P2 stage, possibly in order to focus attention on achieving a fast button press response. Similar between-subjects results were reported by Wascher et al (1996), and were attributed to differences in the allocation of visual attention. Thus, this study has confirmed that warning ERP components other than the late CNV differ between subjects who, on average, respond quickly and those who respond slowly.

The late CNV wave showed the expected centrofrontal maximum, with a focus in the central region contralateral to the responding hand, consistent with reports on the readiness potential (Kornhuber \& Deecke, 1964, 1965; Gilden et al., 1966). In this study there was a tendency for a late CNV increase in the Fast group across the scalp, particularly so in the frontal region, suggesting that between-subject relationships do exist between late CNV and mean RT. Nevertheless, the results also imply that the relationship between RT and late $\mathrm{CNV}$ at $\mathrm{Cz}$ is weaker between- than within-subjects: in this study, the late $\mathrm{CNV}$ at $\mathrm{Cz}$ showed no significant difference between groups $(\mathrm{F}=2.0, \mathrm{p}>.1)$, while in the withinsubjects studies, the same analyses at $\mathrm{Cz}$ have been significant (Hillyard, 1969; Waszak \& Obrist, 1969; Lacey \& Lacey, 1970; Haagh \& Brunia, 1985). Thus, it appears that while late CNV group differences are significant, if one considers topography, those fast vs. slow differences appear to be smaller between- than within-subjects.

This topographic difference in the relationship with RT also has a bearing on the results of the regression, since RT correlated more strongly with late $\mathrm{CNV}$ at Fz $(r=.479, \mathrm{p}=.006)$ 
than $\mathrm{Cz}(r=.367, \mathrm{p}=.039)$. This may reflect the different contributions from frontal and prefrontal areas reported by imaging studies (e.g., D’Esposito et al., 2000; Watanabe et al., 2002; Gomez et al., 2003). However, we chose late CNV at Cz as a predictor variable since it was the site of maximum amplitude across all subjects, in keeping with the method for selecting the other predictor variables. Despite this, the regression analysis of reaction time showed that a larger late $\mathrm{CNV}$ at $\mathrm{C} z$ was indeed associated with faster mean RT. In fact, the correlation between RT and late $\mathrm{CNV}$ at $\mathrm{Cz}$ in this study, $r=.367$, is remarkably close to that reported in a literature summary by Rebert and Tecce (1973), $r=.365$, supporting the idea of a weak but consistent relationship between the level of preparation for a motor response, and the speed of that response. The lack of significance in other amplitude measures is mostly in line with studies reviewed earlier: as with the present between-subjects data, no significant within-subjects relationships between N1/P2 and RT were found by Hillyard (1969), Waszak and Obrist (1969) and Näätänen and Gaillard (1974). However, while some researchers found that larger early CNV amplitude was linked to faster reaction times (Connor \& Lang, 1969; Gaillard, 1976; Haagh \& Brunia, 1985), and others found no relationship (Rohrbaugh et al., 1976; Brunia \& Vingerhoets, 1980; Wascher et al., 1996; Werre et al., 2001), our regression coefficients indicated that a smaller early CNV was related to fast responding, although the unique contribution of this measure was not significant. In sum, the results of this study are generally compatible with previous research, where RT shows a weak but consistent relationship with late $\mathrm{CNV}$, and although group differences are apparent in the amplitude of other components, these do not contribute significantly to mean RT.

Perhaps the most important finding relating pre-S2 processes to RT is the contribution of S1-P2 latency to the regression model. Although the unique contribution only approached significance $(\mathrm{p}=.064)$, the potential contribution of S1-P2 latency to reaction time is worthy of note, and further work is needed to replicate/clarify this result.

The global S2-N2 amplitude was larger after NoGo than Go stimuli, but the effect only approached significance $(\mathrm{p}=.060)$. One reason for the failure to reach significance may be that the N2 NoGo effect is smaller with auditory than visual stimuli (e.g., Falkenstein et al., 1995; Falkenstein et al., 1999), although Nieuwenhuis et al. (2004) have suggested that this 
modality difference may be due to the perceptual similarity of stimuli used in those studies. Alternatively, one might argue that the failure of the NoGo N2 effect to reach significance is due to the task used in this study - that it did not elicit substantial inhibitory processing since the Go response was not prepotent (being equiprobable with NoGo stimuli), and few commission errors were made to NoGo stimuli. However, previous researchers have considered that an equiprobable Go/NoGo task does elicit inhibition and a significant NoGo $\mathrm{N} 2$ effect, and low rates of commission errors are a common finding in the Go/NoGo task (e.g., 1.2\% in Falkenstein et al., 2002; 4.2\% in Roberts et al., 1994; 2.3\% in Fallgatter \& Strik, 1997, compared with 3.2\% here). Therefore, if it is accepted that an equiprobable Go/NoGo task requires inhibition to withhold responses on NoGo trials, then larger N2 amplitudes should be observed on NoGo trials if the NoGo N2 effect reflects inhibition.

The S2-P3 peak showed a centroparietal maximum, and a slight right hemispheric lateralization across the scalp. We also found the typical anterior shift of the NoGo P3 focus, with larger amplitudes than Go at frontal and central, but not parietal, sites (e.g., Kok, 1986; Eimer, 1993; Roberts et al., 1994; Falkenstein et al., 1995; Bekker et al., 2004; TekokKilic et al., 2001). One might argue that this effect is due to overlap with movement-related potentials on Go but not NoGo trials, yet this idea has been discounted: previous studies have shown that this effect occurs whether the instructed task is to count or to button press in response to Go stimuli (Pfefferbaum et al., 1985; Bruin \& Wijers, 2002).

Regression analyses showed that the raw amplitude of the frontocentral NoGo P3 was related to levels of prior preparation (the late $\mathrm{CNV}$ ). However, a separate regression showed that the Go P3 was also marginally predictable from the late CNV. Does this mean that CNV resolution, or the return of the negative shift to baseline, produces the P3? Some researchers (e.g., Jodo \& Inoue, 1990; Eimer, 1993; Roberts et al., 1994; but especially Simson et al., 1977) have proposed that CNV resolution accounts for the NoGo P3 anterior shift. However, if resolution of the late CNV was entirely responsible for the Go/NoGo P3 topography differences, then late CNV should have been a significant contributor to this anterior-posterior gradient difference. This was not the case, with the overall regression only approaching significance, and late $\mathrm{CNV}$ was not a significant predictor. Thus, together, the regressions showed that the frontocentral amplitude of the NoGo P3 increased with levels 
of prior preparation, but this topographic difference is not solely due to differences in CNV resolution on Go and NoGo trials (see also Oddy et al., 2005).

Our main concern in this study was to examine the relationship of inhibitory components to reaction time and response preparation. Analyses of the late CNV showed that participants prepared responses in the foreperiod, and that this was related to fast responding.

Differences in perceptual efficiency cannot explain the observed variation in reaction time between groups, as evidenced by the sensitivity and bias results. It was argued above that if a component reflects inhibition, then it should be affected by the mean speed of response, that is, the NoGo effect should be greater in the Fast group, and it should be related to events in the foreperiod, particularly the response preparation indicated by the late CNV. While a marginal NoGo N2 effect was observed, it was not significantly larger in the Fast group, and the regression analyses showed that late CNV was unrelated to the size of the N2 NoGo effect at Fz, or the raw NoGo N2 amplitude. The P3 NoGo effect, in contrast, was larger in the Fast than Slow group, and its raw amplitude was greater following high levels of response preparation. If the $\mathrm{N} 2 \mathrm{NoGo}$ effect does not represent inhibition, then the $\mathrm{P} 3$ may be a candidate for that process. This is not the first time that such a proposition has been made: Bruin et al. (2001) used a Posner task to differentially cue Go responses, and ERPs to NoGo stimuli following these cues showed no change in the N2 time range, while the NoGo P3 increased according to the cue. Additionally, results from the stop-signal task indicate that the N2 component is larger on trials where inhibition fails than when it is successful (Dimoska et al., 2003; Kok et al., 2004; Overtoom et al., 2002; Ramautar et al., 2004; van Boxtel et al., 2001), which would not be expected if the N2 indexed motor inhibition, while the P3 is robustly larger on successful trials. Some stop-signal researchers have suggested that the successful-stop P3 might represent inhibitory processes (Bekker et al., 2005; Overtoom et al., 2002), while others have suggested that the onset of the P3 might be a better marker of inhibition (Kok, 2004; Ramautar et al., 2004; see also Donkers \& van Boxtel, 2004; Praamstra \& Seiss, 2005). We do not mean to imply that the issue of the functional significance of the N2 NoGo effect can be resolved with such a simple task as the equiprobable Go/NoGo paradigm used in this study, only that our results raise questions about the inhibitory interpretation of $\mathrm{N} 2$, and that further investigations are required. 
In summary, this study has shown that warning ERP components other than the late CNV differ between Fast and Slow responders, but that reaction time is influenced most by late $\mathrm{CNV}$ and potentially by S1-P2 latency. Despite their greater response preparation, the Fast group did not show a greater N2 NoGo effect than the Slow group, and the magnitude of the N2 NoGo effect at Fz was unrelated to response preparation, leading us to doubt whether the N2 NoGo effect represents inhibition. The P3 NoGo effect may instead be a candidate for this process, since it was larger in Fast responders, increased with levels of prior preparation, yet was not caused by resolution of the CNV. 
Acknowledgements: The authors thank Dale Chiswick, Aneta Dimoska, Diane Pirs, Carly Pleffer, and David Webster for their valuable contributions to this research, and anonymous reviewers for their helpful comments on a previous version. 


\section{References}

Band, G.P.H., Ridderinkhof, K.R., van der Molen, M.W., 2003. Speed-accuracy modulation in case of conflict: the roles of activation and inhibition. Psychol. Res. 67, 266-279.

Bekker, E.M., Kenemans, J.L., \& Verbaten, M.N., 2004. Electrophysiological correlates of attention, inhibition, sensitivity and bias in a continuous performance task. Clin. Neurophysiol. 115, 2001-2013.

Bekker, E.M., Kenemans, J.L., Koeksma, M.R., Talsma, D., \& Verbaten, M.N., 2005. The pure electrophysiology of stopping. Int. J. Psychophysiol. 55, 191-198.

Bruin, K.J., Wijers, A.A., 2002. Inhibition, response mode, and stimulus probability: a comparative event-related potential study. Clin. Neurophysiol. 113, 1172-1182.

Bruin, K.J., Wijers, A.A., van Staveren, A.S.J., 2001. Response priming in a go/nogo task:

Do we have to explain the go/nogo N2 effect in terms of response activation instead of inhibition? Clin. Neurophysiol. 112, 1660-1671.

Brunia, C.H.M., Vingerhoets, A.J.J.M., 1980. CNV and EMG preceding a plantar flexion of the foot. Biol. Psychol. 11, 181-191.

Connor, W.H., Lang, P.J., 1969. Cortical slow-wave and cardiac rate responses in stimulus orientation and reaction time conditions. J Exp. Psychol. 82, 310-320.

Damen, E.J.P., Brunia, C.H.M., 1987. Changes in heart rate and slow brain potentials related to motor preparation and stimulus anticipation in a time estimation task.

Psychophysiology 24, 700-713.

De Jong, R., Coles, M.G.H., Logan, G.D., Gratton, G., 1990. In search of the point of no return: the control of response processes. J. Exp. Psychol. Hum. Percept. Perform. 16, 164-182.

D'Esposito, M., Ballard, D., Zarahn, E., Aguirre, G.K., 2000. The role of prefrontal cortex in sensory memory and motor preparation: an event-related fMRI study. Neuroimage $11,400-408$.

Dimoska, A., Johnstone, S.J., Barry, R.J., Clarke, A.R., 2003. Inhibitory motor control in children with Attention-deficit/Hyperactivity Disorder: Event-related potentials in the stop-signal paradigm. Biol. Psychiat. 54, 1340-1349. 
Donkers, F. C. L., van Boxtel, G. J. M., 2004. The N2 in go/no-go tasks reflects conflict monitoring not response inhibition. Brain \& Cog. 56, 165-176.

Eimer, M., 1993. Effects of attention and stimulus probability on ERPs in a Go/Nogo task. Biol. Psychiat. 35, 123-138.

Falkenstein, M., Hoormann, J., Hohnsbein, J., 1999. ERP components in Go/Nogo tasks and their relation to inhibition. Acta Psychol. (Amst.) 101, 267-291.

Falkenstein, M., Hoormann, J., Hohnsbein, J., 2002. Inhibition-related ERP components: variation with modality, age, and time-on-task. J Psychophysiol. 16, 167-175.

Falkenstein, M., Koshlykova, N.A., Kiroj, V.N., Hoormann, J., Hohnsbein, J., 1995. Late ERP components in visual and auditory Go/Nogo tasks. EEG Clin. Neurophysiol.: Evoked Potentials 96, 36-43.

Fallgatter, A.J., Brandeis, D., \& Strik, W.K., 1997. A robust assessment of the NoGoanteriorisation of $\mathrm{P} 300$ microstates in a cued-continuous performance task. Brain Topog. 9, 295-302.

Fallgatter, A.J., Strik, W.K., 1999. The NoGo-anteriorisation as a neurophysiological standard-index for cognitive response control. Int. J. Psychophysiol. 32, 233-238.

Filipovic, S.R., Jahanshahi, M., Rothwell, J.C., 1999. Cortical potentials related to decisionmaking: Comparison of two types of go/nogo decision. Neuroreport 10, 3583-3587.

Filipovic, S.R., Jahanshahi, M., Rothwell, J.C., 2000. Cortical potentials related to the nogo decision. Exp. Brain Res. 132, 411-415.

Gaillard, A.W.K., 1976. Effects of warning-signal modality on the contingent negative variation (CNV). Biol. Psychol. 4, 139-154.

Gilden, L., Vaughan, H.G., Costa, L.D., 1966. Summated human EEG potentials with voluntary movement. EEG Clin. Neurophysiol. 20, 433-438.

Gomez, C.M., Marco, J., Grau, C., 2003. Preparatory visuo-motor cortical network of the contingent negative variation estimated by current density. Neuroimage 20, 216-224.

Haagh, S.A.V.M., Brunia, C.H.M., 1985. Anticipatory response-relevant muscle activity, CNV amplitude and simple reaction time. EEG Clin. Neurophysiol. 61, 30-39.

Hegerl, U., Juckel, G., 1993. Intensity dependence of auditory evoked potentials as an indicator of central serotonergic neurotransmission: A new hypothesis. Biol Psychiat. 33, 173-187. 
Heil, M., Osman, A., Wiegelmann, J., Rolke, B., \& Hennighausen, E., 2000. N200 in the Eriksen-task: Inhibitory executive processes? J. Psychophysiol. 14, 218-225.

Hillyard, S.A., 1969. Relationships between the contingent negative variation (CNV) and reaction time. Physiol. Behav. 4, 351-357.

Hillyard, S.A., Galambos, R., 1967. Effects of stimulus and response contingencies on a surface negative slow potential shift in man. EEG Clin. Neurophysiol. 22, 297-304.

Irwin, D.A., Knott, J.R., McAdam, D.W., Rebert, C.S., 1966. Motivational determinants of the "Contingent Negative Variation". EEG Clin. Neurophysiol. 21, 538-543.

Jodo, E., Inoue, K., 1990. Effects of practice on the P300 in a Go/NoGo task. EEG Clin. Neurophysiol. 76, 249-257.

Jodo, E., Kayama, Y., 1992. Relation of a negative ERP component to response inhibition in a Go/No-go task. EEG Clin. Neurophysiol. 82, 477-482.

Kayser, J., Tenke, C.E., 2003. Optimising PCA methodology for ERP component identification and measurement: Theoretical rationale and empirical evaluation. Clin. Neurophysiol. 114, 2307-2325.

Kok, A., 1986. Effects of degradation of visual stimuli on components of the event-related potential (ERP) in go/nogo reaction tasks. Biol. Psychol. 23, 21-38.

Kok, A., Ramautar, J.R., De Ruiter, M.B., Band, G.P.H., Ridderinkhof, K.R., 2004. ERP components associated with successful and unsuccessful stopping in a stop-signal task. Psychophysiology 41, 9-20.

Kopp, B., Mattler, U., Goertz, R., Rist, F., 1996. N2, P3 and the lateralised readiness potential in a nogo task involving selective response priming. EEG Clin. Neurophysiol. 99, 19-27.

Kopp, B., Rist, F., \& Mattler, U., 1996. N200 in the flanker task as a neurobehavioral tool for investigating executive control. Psychophysiology 33, 282-294.

Kornhuber, H.H., Deecke, L., 1964. Hirnpotentialanderungen beim Menschen vor und nach Willkurbewegungen, dargestellt mit Magnetbandspeicherung und Ruckwartsanalyse. Pflugers Archiv 281, 52.

Kornhuber, H.H., Deecke, L., 1965. Hirnpotentialanderungen bei Willkurbewegungen und passive bewegungen des menschen: Bereitschaftspotential une reafferente potentiale. Pflugers Archiv 284, 1-17. 
Lacey, J.I., Lacey, B.C., 1970. Some autonomic-central nervous system interrelationships. In: Black, P. (Ed.), Physiological correlates of emotion. Academic Press, London, pp. 205-227.

Lombroso, C.T., 1969. The CNV during tasks requiring choice. In: Evans, C.R., Mulholland, T.B. (Eds.), Attention in Neurophysiology, Butterworths, London, pp. 64-69.

Loveless, N.E., 1979. Event-related slow potentials of the brain as expressions of orienting function. In: Kimmel, H.D., van Olst, E.H., Orlebeke, J.F. (Eds.), The Orienting Reflex in Humans, Lawrence Erlbaum Associates, New Jersey, pp. 77-100.

Macmillan, N. A., Creelman, C. D., 1991. Detection theory: A user's guide. Cambridge, England: Cambridge University Press.

Macmillan, N. A., Kaplan, H. L., 1985. Detection theory analysis of group data: estimating sensitivity from average hit and false-alarm rates. Psychol Bull. 98, 185-199.

McCarthy, G., Wood, C.C., 1985. Scalp distributions of event-related potentials: An ambiguity associated with analysis of variance models. EEG Clin. Neurophysiol. 62, 203-208.

Näätänen, R., Gaillard, A.W.K., 1974. The relationship between the contingent negative variation and the reaction time under prolonged experimental conditions. Biol. Psychol. 1, 277-291.

Näätänen, R., Picton, T.W., 1987. The N1 wave of the human electric and magnetic response to sound: A review and an analysis of the component structure. Psychophysiology 24, 375-425.

Nieuwenhuis, S., Yeung, N., Cohen, J.D., 2004. Stimulus modality, perceptual overlap, and the go/no-go N2. Psychophysiology 41, 157-160.

Nieuwenhuis, S., Yeung, N., van den Wildenburg, W., Ridderinkhof, K.R., 2003. Electrophysiological correlates of anterior cingulate function in a go/nogo task: Effects of response conflict and trial type frequency. Cognit. Affect. Behav. Neurosci. 3, 17-26.

Oades, R.D., 1998. Frontal, temporal and lateralised brain function in children with attention-deficit hyperactivity disorder: a psychophysiological and neuropsychological viewpoint on development. Behav. Brain Res. 94, 83-95. 
Oddy, B.W., Barry, R.J., Johnstone, S.J., Clarke, A.R., 2005. Removal of CNV effects from the N2 and P3 ERP components in a visual Go/NoGo task. J Psychophysiol. 19, 2434.

Overtoom, C.C.E., Kenemans, J.L., Verbaten, M.N., Kemner, C., van der Molen, M.W., van Engeland, H., Buitelaar, J.K., Koelega, H.S., 2002. Inhibition in children with attention-deficit/hyperactivity disorder: A psychophysiological study of the stop task. Biol. Psychiat. 51, 668-676.

Papakostopoulos, D., Fenelon, B., 1975. Spatial distribution of the contingent negative variation $(\mathrm{CNV})$ and the relationship between $\mathrm{CNV}$ and reaction time.

Psychophysiology 12, 74-78.

Peters, J.F., Knott, J.R., Miller, L.H., Van Veen, W.J., Cohen, S.I., 1970. Response variables and magnitude of the contingent negative variation. EEG Clin. Neurophysiol. 29, 608-611.

Pfefferbaum, A., Ford, J.M., 1988. ERPs to stimuli requiring response production and inhibition: effects of age, probability and visual noise. EEG Clin. Neurophysiol. 71, $55-63$.

Pfefferbaum, A., Ford, J.M., Weller, B.J., Kopell, B.S., 1985. ERPs to response production and inhibition. EEG Clin. Neurophysiol. 60, 423-434.

Picton, T.W., Bentin, S., Berg, P., Donchin, E., Hillyard, S.A., Johnson, R., Miller, G.A., Ritter, W., Ruchkin, D.S., Rugg, M.D., Taylor, M.J., 2000. Guidelines for using human event-related potentials to study cognition: Recording standards and publication criteria. Psychophysiology 37, 127-152.

Praamstra, P., Seiss, E., 2005. The neurophysiology of response competition: Motor cortex activation and inhibition following subliminal response priming. J Cog. Neuro. 17, 483-493.

Ramautar, J.R., Kok, A., Ridderinkhof, K.R., 2004. Effects of stop-signal probability in the stop-signal paradigm: The N2/P3 complex further validated. Brain and Cog. 56, 234252.

Raven, J., 2000. The Raven's progressive matrices: Changes and stability over culture and time. Cognit. Psychol. 41, 1-48.

Rebert, C.S., Sperry, K.G., 1973. Subjective and response-related determinants of CNV amplitude. Psychophysiology 10, 139-144. 
Rebert, C.S., Tecce, J.J., 1973. A summary of CNV and reaction time. EEG Clin. Neurophysiol. Supplement 33, 173-178.

Roberts, L.E., Rau, H., Lutzenberger, W., Birbaumer, N., 1994. Mapping P300 waves onto inhibition: Go/No-Go discrimination. EEG Clin. Neurophysiol. 92, 44-55.

Rohrbaugh, J.W., Syndulko, K., Lindsley, D.B., 1976. Brain wave components of the contingent negative variation in humans. Science 191, 1055-1057.

Simson, R., Vaughan, H.G., Ritter, W., 1977. The scalp topography of potentials in auditory and visual go/nogo tasks. EEG Clin. Neurophysiol. 43, 864-875.

Tabachnick, B.G., Fidell, L.S., 1996. Using multivariate statistics. HarperCollins, New York.

Tekok-Kilic, A., Shucard, J.L., Shucard, D.W., 2001. Stimulus modality and Go/NoGo effects on P3 during parallel visual and auditory continuous performance tasks. Psychophysiology 38, 578-589.

van Boxtel, G.J.M., van der Molen, M.W., Jennings, J.R., Brunia, C.H.M., 2001. A psychophysiological analysis of inhibitory motor control in the stop-signal paradigm. Biol. Psychol. 58, 229-262.

Walter, W.G., Cooper, R., Aldridge, V.J., McCallum, W.C., Winter, A.L., 1964. Contingent negative variation: an electric sign of sensorimotor association and expectancy in the human brain. Nature 203, 380-384.

Wang, Y., Tian, S., Wang, H., Cui, L., \& Zhang, Y., 2002. Event-related potentials in a no-go task involving response-tendency conflict. Clin. Electroenceph. 33, 82-85.

Wascher, E., Verleger, R., Jaskowski, P., Wauschkuhn, B., 1996. Preparation for action: An ERP study about two tasks provoking variability in response speed.

Psychophysiology 33, 262-272.

Waszak, M., Obrist, W.D., 1969. Relationship of slow potential changes to response speed and motivation in man. EEG Clin. Neurophysiol. 27, 113-120.

Watanabe, J., Sugiura, M., Sato, K., Sato, Y., Maeda, Y., Matsue, Y., Fukuda, H., Kawashima, R., 2002. The human prefrontal and parietal association cortices are involved in NoGo performances: an event-related fMRI study. Neuroimage 17, 1207-1216.

Werre, P.F., Mattie, H., Berretty, E.W., 2001. Contingent negative variation, extraversion, reaction time and drug effects. Pers. Individ. Differ 30, 1083-1094. 
Table 1. Peak latency search windows, site of peak detection, and mean latency for Fast and Slow groups, and Go and NoGo types.

\begin{tabular}{|c|c|c|c|c|c|c|}
\hline \multirow{2}{*}{ Component } & \multirow{2}{*}{ Search window (ms) } & \multirow{2}{*}{ Site } & \multicolumn{2}{|c|}{ Fast } & \multicolumn{2}{|c|}{ Slow } \\
\hline & & & Go & NoGo & Go & NoGo \\
\hline S1-N1 & $75-150$ & $\mathrm{Fz}$ & \multicolumn{2}{|c|}{112.5} & \multicolumn{2}{|c|}{116.7} \\
\hline S1-P2 & $180-280$ & $\mathrm{Pz}$ & \multicolumn{2}{|c|}{235.2} & \multicolumn{2}{|c|}{227.6} \\
\hline S2-N2 & $170-250$ & $\mathrm{Fz}$ & 203.4 & 187.8 & 204.3 & 211.3 \\
\hline S2-P3 & $280-500$ & $\mathrm{Pz}$ & 325.2 & 342.4 & 350.3 & 359.2 \\
\hline
\end{tabular}


Table 2. Group means for participant data and behavioural performance, and significance of group differences.

\begin{tabular}{|l|c|c|c|c|}
\hline & Fast & Slow & \multicolumn{1}{|c|}{ F } & P \\
\hline Age (years) & 23.8 & 24.4 & $<1$ & .761 \\
\hline SPM Score & 118.8 & 115.6 & $<1$ & .566 \\
\hline Go RT (ms) & 321.6 & 439.4 & 46.0 & .001 \\
\hline Go RT SD (ms) & 61.4 & 103.2 & 15.2 & .001 \\
\hline Go Accuracy (\%) & 99.6 & 98.8 & 1.3 & .262 \\
\hline NoGo Accuracy (\%) & 96.6 & 97.1 & $<1$ & .858 \\
\hline Warning Accuracy (\%) & 100 & 99.9 & 1.0 & .325 \\
\hline Sensitivity (d') & 4.0 & 3.9 & $<1$ & .457 \\
\hline Bias (ln $\beta$ ) & -0.21 & -0.24 & $<1$ & .907 \\
\hline
\end{tabular}


Table 3. Significant results for ERP components to warning stimuli

\begin{tabular}{|c|c|c|c|c|c|}
\hline Measure & Effect & Contrast & Details & $\mathrm{F}$ & $\mathrm{P}$ \\
\hline \multirow[t]{5}{*}{ S1-N1 } & $\mathrm{S}$ & f vs. p & -8.7 vs. -3.5 & 96.7 & .001 \\
\hline & & c vs. $\mathrm{f} / \mathrm{p}$ & -7.7 vs. -6.1 & 86.7 & .001 \\
\hline & $\mathrm{L}$ & $\mathrm{m}$ vs. $1 / \mathrm{r}$ & -7.3 vs. -6.3 & 61.2 & .001 \\
\hline & $\mathrm{LxS}$ & $\begin{array}{l}\mathrm{Cz} \text { to } \mathrm{C} 3 / \mathrm{C} 4 \text { vs. } \\
\mathrm{Fz} / \mathrm{Pz} \text { to } \mathrm{F} 3 \mathrm{~F} 4 / \mathrm{P} 3 \mathrm{P} 4\end{array}$ & -8.5 to -7.3 vs. -6.7 vs. -5.7 & 4.2 & .048 \\
\hline & G & Fast vs. Slow & -5.4 vs. -7.9 & 8.9 & .006 \\
\hline \multirow[t]{8}{*}{ S1-P2 } & $\mathrm{S}$ & f vs. p & 0.3 vs. 3.6 & 61.9 & .001 \\
\hline & & c vs. f/p & 2.5 vs. 2.0 & 11.4 & .001 \\
\hline & $\mathrm{L}$ & $\mathrm{m}$ vs. $1 / \mathrm{r}$ & 2.8 vs. 1.8 & 66.2 & .001 \\
\hline & $\mathrm{LxS}$ & F3 to F4 vs. P3 to P4 & 0.4 to 0.0 vs. 3.1 vs. 3.2 & 4.9 & .035 \\
\hline & & $\begin{array}{l}\text { Fz to F3/F4 vs. Pz to } \\
\text { P3/P4 }\end{array}$ & 0.5 to 0.2 vs. 4.6 to 3.2 & 42.8 & .001 \\
\hline & & $\begin{array}{l}\mathrm{Cz} \text { to } \mathrm{C} 3 / \mathrm{C} 4 \text { vs. } \\
\mathrm{Fz} / \mathrm{Pz} \text { to } \mathrm{F} 3 \mathrm{~F} 4 / \mathrm{P} 3 \mathrm{P} 4\end{array}$ & 3.5 to 2.1 vs. 2.5 to 1.7 & 11.4 & .002 \\
\hline & $\mathrm{LxG}$ & lvs. $\mathrm{r}$ & $\begin{array}{l}\text { Fast: } 2.2 \text { vs. } 2.4 \\
\text { Slow: } 1.7 \text { vs. } 1.0\end{array}$ & 6.5 & .016 \\
\hline & $\mathrm{LxSxG}$ & $\begin{array}{l}\text { C3 to C4 vs. F3/P3 to } \\
\text { F4/P4 }\end{array}$ & $\begin{array}{l}\text { Fast: } 2.5 \text { to } 2.8 \text { vs. } 2.0 \text { to } 2.2 \\
\text { Slow: } 2.0 \text { to } 1.0 \text { vs. } 1.5 \text { to } 1.0\end{array}$ & 4.4 & .044 \\
\hline \multirow{6}{*}{$\begin{array}{l}\text { Early } \\
\text { CNV }\end{array}$} & $\mathrm{S}$ & f vs. $p$ & -3.6 vs. -0.8 & 66.2 & .001 \\
\hline & & c vs. f/p & -2.8 vs. -2.2 & 17.7 & .001 \\
\hline & $\mathrm{L}$ & $\mathrm{m}$ vs. $1 / \mathrm{r}$ & -2.7 vs. -2.3 & 23.8 & .001 \\
\hline & $\mathrm{LxS}$ & $\begin{array}{l}\text { Fz to F3/F4 vs. Pz to } \\
\text { P3/P4 }\end{array}$ & -3.9 to -3.5 vs. -0.9 to -0.7 & 4.2 & .049 \\
\hline & & $\begin{array}{l}\mathrm{Cz} \text { to } \mathrm{C} 3 / \mathrm{C} 4 \text { vs. } \\
\mathrm{Fz} / \mathrm{Pz} \text { to } \mathrm{F} 3 \mathrm{~F} 4 / \mathrm{P} 3 \mathrm{P} 4\end{array}$ & -3.3 to -2.5 vs. -2.4 to -2.1 & 20.9 & .001 \\
\hline & $\mathrm{LxSxG}$ & $\begin{array}{l}\text { Fz to F3/F4 vs. Pz to } \\
\text { P3/P4 }\end{array}$ & $\begin{array}{l}\text { Fast: }-3.7 \text { to }-3.1 \text { vs. }-0.8 \text { to }-0.7 \\
\text { Slow: }-4.1 \text { to }-3.9 \text { vs. }-1.0 \text { to }-0.7\end{array}$ & 3.8 & .060 \\
\hline \multirow{8}{*}{$\begin{array}{l}\text { Late } \\
\text { CNV } \\
\end{array}$} & $\mathrm{S}$ & f vs. p & -5.0 vs. -3.1 & 26.8 & .001 \\
\hline & & & & & \\
\hline & & c vs. f/p & -5.5 vs. -4.0 & 53.7 & .001 \\
\hline & $\mathrm{L}$ & $\mathrm{m}$ vs. $1 / \mathrm{r}$ & -4.9 vs. -4.3 & 20.8 & .001 \\
\hline & $\mathrm{LxS}$ & $\begin{array}{l}\mathrm{C} 3 \text { to } \mathrm{C} 4 \text { vs. } \mathrm{F} 3 / \mathrm{P} 3 \text { to } \\
\mathrm{F} 4 / \mathrm{P} 4\end{array}$ & -5.2 to -4.9 vs. -3.9 to -3.9 & 4.7 & .038 \\
\hline & & $\begin{array}{l}\mathrm{Cz} \text { to } \mathrm{C} 3 / \mathrm{C} 4 \text { vs. } \\
\mathrm{Fz} / \mathrm{Pz} \text { to } \mathrm{F} 3 \mathrm{~F} 4 / \mathrm{P} 3 \mathrm{P} 4\end{array}$ & -6.3 to -5.1 vs. -4.3 to -3.9 & 17.7 & .001 \\
\hline & G & Fast vs. Slow & -5.3 vs. -3.7 & 3.0 & .091 \\
\hline & $\mathrm{LxSxG}$ & $\begin{array}{l}\text { Fz to F3/F4 vs. Pz to } \\
\text { P3/P4 }\end{array}$ & $\begin{array}{l}\text { Fast: }-6.8 \text { to }-5.8 \text { vs. }-3.6 \text { to }-3.3 \\
\text { Slow: }-3.9 \text { to }-3.9 \text { vs. }-2.9 \text { to }-2.6\end{array}$ & 6.6 & .016 \\
\hline
\end{tabular}

Details column represents mean amplitude in microvolts. G, Group: Fast vs. Slow. Lateral (L) abbreviations: 1, mean left hemisphere (F3, C3, P3); r, mean right hemisphere (F4, C4, P4); 1/r, mean of the left and right hemispheres (F3, C3, P3, F4, C4, P4); m, mean of the midline (Fz, Cz, Pz). Sagittal (S) abbreviations: f, mean frontal (F3, Fz, F4); p, mean parietal (P3, Pz, P4); c, mean central (C3, Cz, C4); f/p, mean of frontal and parietal (F3, Fz, F4, P3, Pz, P4). Lateral by Sagittal (LxS) 
interactions: sites (e.g. F3) represent position on scalp (e.g. frontal left hemisphere); F3/P3, mean of frontal and parietal left hemisphere; F4/P4, mean of frontal and parietal right hemisphere; $\mathrm{Fz} / \mathrm{Pz}$, mean of frontal and parietal midline; F3/F4, mean of frontal left and right hemispheres; P3/P4, mean of parietal left and right hemispheres; $\mathrm{C} 3 / \mathrm{C} 4$, mean of central left and right hemispheres; $\mathrm{F} 3 \mathrm{~F} 4 / \mathrm{P} 3 \mathrm{P} 4$, mean of frontal and parietal left and right hemispheres. 
Table 4. Significant results for ERP components to Go/NoGo stimuli

\begin{tabular}{|c|c|c|c|c|c|}
\hline Measure & Effect & Contrast & Details & $\mathrm{F}$ & $\mathrm{P}$ \\
\hline \multirow{10}{*}{ S2-N2 } & $\mathrm{S}$ & f vs. p & -4.6 vs. 1.3 & 59.9 & .001 \\
\hline & $\mathrm{L}$ & m vs. $1 . / \mathrm{r}$ & -1.1 vs. -1.8 & 19.6 & .001 \\
\hline & $\mathrm{LxS}$ & $\begin{array}{l}\text { C3 to } \mathrm{C} 4 \text { vs. F3/P3 to } \\
\text { F4/P4 }\end{array}$ & -2.2 to -1.5 vs. -1.8 to -1.8 & 14.2 & .001 \\
\hline & & $\begin{array}{l}\text { Fz to F3/F4 vs. Pz to } \\
\text { P3/P4 }\end{array}$ & -4.7 to -4.5 vs. 2.0 to 0.9 & 25.8 & .001 \\
\hline & & $\begin{array}{l}\mathrm{Cz} \text { to } \mathrm{C} 3 / \mathrm{C} 4 \text { vs. } \\
\mathrm{Fz} / \mathrm{Pz} \text { to } \mathrm{F} 3 \mathrm{~F} 4 / \mathrm{P} 3 \mathrm{P} 4\end{array}$ & -0.5 to 1.8 vs. -1.4 to -1.8 & 20.6 & .001 \\
\hline & $\mathrm{T}$ & Go vs. NoGo & -0.7 vs. -2.4 & 3.8 & .060 \\
\hline & TxS & c vs. $\mathrm{f} / \mathrm{p}$ & $\begin{array}{l}\text { Go: }-0.9 \text { vs. }-0.6 \\
\text { NoGo: }-1.9 \text { vs. }-2.7\end{array}$ & 23.4 & .001 \\
\hline & TxL & l vs. $\mathrm{r}$ & $\begin{array}{l}\text { Go: }-1.4 \text { vs. }-0.6 \\
\text { NoGo: }-2.5 \text { vs. }-2.7\end{array}$ & 9.3 & .005 \\
\hline & TxLxS & $\begin{array}{l}\text { C3 to C4 vs. F3/P3 to } \\
\text { F4/P4 }\end{array}$ & $\begin{array}{l}\text { Go: }-2.2 \text { to }-0.6 \text { vs. }-1.0 \text { to }-0.6 \\
\text { NoGo: }-2.1 \text { to }-2.4 \text { vs. }-2.6 \text { to }-2.9\end{array}$ & 19.7 & .001 \\
\hline & $\mathrm{SxG}$ & c vs. $\mathrm{f} / \mathrm{p}$ & $\begin{array}{l}\text { Fast: }-0.4 \text { vs. }-1.1 \\
\text { Slow: }-2.4 \text { vs. }-2.2\end{array}$ & 6.5 & .016 \\
\hline \multirow[t]{18}{*}{ S2-P3 } & $\mathrm{S}$ & f vs. p & 6.0 vs. 13.0 & 76.7 & .001 \\
\hline & & c vs. $\mathrm{f} / \mathrm{p}$ & 11.8 vs. 9.5 & 72.7 & .001 \\
\hline & $\mathrm{L}$ & lvs. $\mathrm{r}$ & 9.1 vs. 9.9 & 6.2 & .018 \\
\hline & & $\mathrm{m}$ vs. $1 / \mathrm{r}$ & 11.8 vs. 9.5 & 138.0 & .001 \\
\hline & $\mathrm{LxS}$ & $\begin{array}{l}\text { C3 to C4 vs. F3/P3 to } \\
\text { F4/P4 }\end{array}$ & 10.0 vs. 11.3 vs. 8.7 to 9.2 & 14.2 & .001 \\
\hline & & $\begin{array}{l}\text { Fz to F3/F4 vs. Pz to } \\
\text { P3/P4 }\end{array}$ & 6.3 to 5.8 vs. 14.9 to 12.1 & 119.5 & .001 \\
\hline & & $\begin{array}{l}\mathrm{Cz} \text { to } \mathrm{C} 3 / \mathrm{C} 4 \text { vs. } \\
\mathrm{Fz} / \mathrm{Pz} \text { to } \mathrm{F} 3 \mathrm{~F} 4 / \mathrm{P} 3 \mathrm{P} 4\end{array}$ & 14.1 to 10.6 vs. 10.6 to 8.9 & 55.4 & .001 \\
\hline & TxS & f vs. p & $\begin{array}{l}\text { Go: } 4.7 \text { vs. } 13.5 \\
\text { NoGo: } 7.2 \text { vs. } 12.6\end{array}$ & 11.7 & .002 \\
\hline & & c vs. $\mathrm{f} / \mathrm{p}$ & $\begin{array}{l}\text { Go: } 10.8 \text { vs. } 9.1 \\
\text { NoGo: } 12.7 \text { vs. } 9.9\end{array}$ & 10.0 & .004 \\
\hline & TxL & l vs. $r$ & $\begin{array}{l}\text { Go: } 8.4 \text { vs. } 9.7 \\
\text { NoGo: } 9.9 \text { vs. } 10.1\end{array}$ & 6.4 & .017 \\
\hline & & $\mathrm{m}$ vs. $1 / \mathrm{r}$ & $\begin{array}{l}\text { Go: } 11.0 \text { vs. } 9.0 \\
\text { NoGo: } 12.6 \text { vs. } 10.0\end{array}$ & 6.8 & .014 \\
\hline & TxLxS & F3 to F4 vs. P3 to P4 & $\begin{array}{l}\text { Go: } 4.1 \text { to } 5.3 \text { vs. } 12.3 \text { to } 12.7 \\
\text { NoGo: } 7.0 \text { to } 6.7 \text { vs. } 11.4 \text { to } 12.0\end{array}$ & 16.0 & .001 \\
\hline & & $\begin{array}{l}\text { C3 to C4 vs. F3/P3 to } \\
\text { F4/P4 }\end{array}$ & $\begin{array}{l}\text { Go: } 8.7 \text { to } 11.0 \text { vs. } 8.2 \text { to } 9.0 \\
\text { NoGo: } 11.2 \text { to } 11.5 \text { vs. } 9.2 \text { to } 9.4\end{array}$ & 10.4 & .003 \\
\hline & & $\begin{array}{l}\text { Fz to F3/F4 vs. Pz to } \\
\text { P3/P4 }\end{array}$ & $\begin{array}{l}\text { Go: } 4.8 \text { to } 4.7 \text { vs. } 15.5 \text { to } 12.5 \\
\text { NoGo: } 7.9 \text { to } 6.9 \text { vs. } 14.4 \text { to } 11.7\end{array}$ & 7.0 & .013 \\
\hline & & $\begin{array}{l}\text { Cz to } \mathrm{C} 3 / \mathrm{C} 4 \text { vs. } \\
\mathrm{Fz} / \mathrm{Pz} \text { to F3F4/P3P4 }\end{array}$ & $\begin{array}{l}\text { Go: } 12.7 \text { to } 9.9 \text { vs. } 10.1 \text { to } 8.6 \\
\text { NoGo: } 15.5 \text { to } 11.4 \text { vs. } 11.1 \text { to } 9.3\end{array}$ & 7.1 & .013 \\
\hline & G & Fast vs. Slow & 11.8 vs. 8.8 & 4.2 & .049 \\
\hline & SxG & c vs. f/p & $\begin{array}{l}\text { Fast: } 13.9 \text { vs. } 10.7 \\
\text { Slow: } 9.6 \text { vs. } 8.3\end{array}$ & 13.8 & .001 \\
\hline & TxSxG & f vs. p & \begin{tabular}{l|l} 
Fast & Go: 5.5 vs. 14.3 \\
\end{tabular} & 4.6 & .040 \\
\hline
\end{tabular}




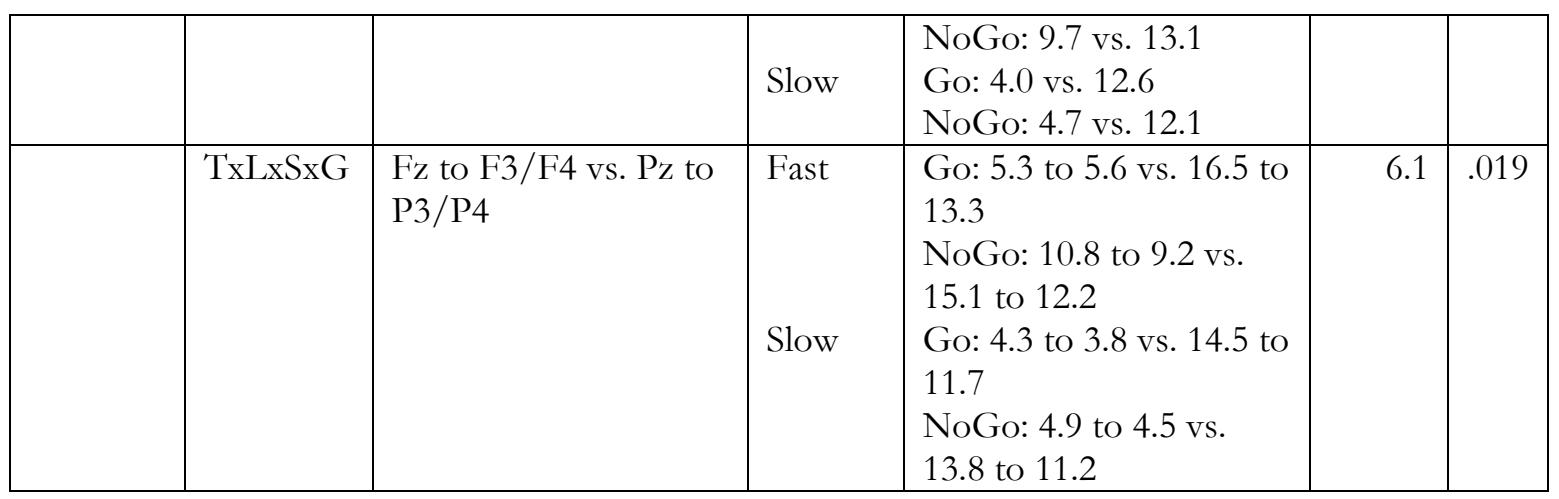

As with Table 3, also T, Type: Go vs. NoGo. 
Table 5. Full correlation of predictor variables

\begin{tabular}{|l|l|l|l|l|c|c|c|c|c|c|}
\hline & \multicolumn{2}{|c|}{ S1-N1 amp at Fz } & \multicolumn{2}{l|}{ S1-N1 latency } & S1-P2 amp at Pz & \multicolumn{2}{l|}{ S1-P2 latency } & \multicolumn{2}{c|}{ Early CNV at Fz } \\
\hline S1-N1 latency & .168 & & & & & & & & & \\
\hline S1-P2 amp at Pz & .236 & & .128 & & & & & & & \\
\hline S1-P2 latency & .288 & & .340 & & .259 & & & & & \\
\hline Early CNV at Fz & .386 & $*$ & .303 & & .526 & $* *$ & .253 & & & \\
\hline Late CNV at Cz & .018 & & .254 & & .204 & & .378 & $*$ & .585 & $* * *$ \\
\hline
\end{tabular}

Note: significance levels indicated by asterisks: * denotes $\mathrm{p}<.05$, ** denotes $\mathrm{p}<.01$, *** denotes $\mathrm{p}<.001$ 
Table 6. Results of regression analyses

\begin{tabular}{|c|c|c|c|c|c|c|c|c|c|}
\hline Regression & Significance & $\mathrm{R}$ & Adjusted $\mathrm{R}^{2}$ & Variable & B & SE B & Beta & $\mathrm{t}$ & Sig $t$ \\
\hline \multirow[t]{7}{*}{ RT } & .065 & .598 & .203 & Late CNV Cz & 11.042 & 4.780 & .525 & 2.310 & .029 \\
\hline & & & & Early CNV Fz & -4.957 & 9.143 & -.142 & -.542 & .592 \\
\hline & & & & $\mathrm{N} 1 \mathrm{Fz}$ & -4.949 & 4.838 & -.196 & -1.023 & .316 \\
\hline & & & & $\mathrm{P} 2 \mathrm{Pz}$ & .601 & 5.735 & .021 & .105 & .917 \\
\hline & & & & N1 Lat & .955 & .639 & .264 & 1.495 & .147 \\
\hline & & & & P2 Lat & -.945 & .487 & -.378 & -1.942 & .064 \\
\hline & & & & (Constant) & 491.092 & 145.106 & & 3.384 & .002 \\
\hline \multirow[t]{7}{*}{ S2-N2 } & .207 & .519 & .094 & Late CNV Cz & .666 & .300 & .539 & 2.223 & .035 \\
\hline & & & & Early CNV Fz & -1.232 & .573 & -.602 & -2.151 & .041 \\
\hline & & & & $\mathrm{N} 1 \mathrm{Fz}$ & .184 & .303 & .124 & .606 & .550 \\
\hline & & & & P2 Pz & .326 & .329 & .190 & .908 & .372 \\
\hline & & & & N1 Latency & -.049 & .040 & -.232 & -1.234 & .229 \\
\hline & & & & P2 Latency & -.027 & .031 & -.187 & -.899 & .377 \\
\hline & & & & (Constant) & 14.568 & 9.094 & & 1.602 & .122 \\
\hline \multirow[t]{7}{*}{ NoGo-N2 } & .168 & .536 & .116 & Late CNV Cz & -.663 & .297 & -.534 & -2.230 & .035 \\
\hline & & & & Early CNV Fz & .905 & .568 & .440 & 1.592 & .124 \\
\hline & & & & $\mathrm{N} 1 \mathrm{Fz}$ & -.008 & .301 & -.006 & -.028 & .978 \\
\hline & & & & $\mathrm{P} 2 \mathrm{Pz}$ & -.080 & .357 & -.046 & -.225 & .824 \\
\hline & & & & N1 Latency & -.008 & .040 & -.035 & -.191 & .850 \\
\hline & & & & P2 Latency & .065 & .030 & .441 & 2.149 & .042 \\
\hline & & & & (Constant) & -20.701 & 9.022 & & -2.295 & .030 \\
\hline \multirow[t]{3}{*}{ Go-N2 } & .272 & .495 & .064 & Late $\mathrm{CNV} \mathrm{Cz}$ & .003 & .231 & .004 & .014 & .989 \\
\hline & & & & Early CNV Fz & -.328 & .442 & -.211 & -.742 & .465 \\
\hline & & & & N1 Fz & .175 & .234 & .156 & .750 & .460 \\
\hline
\end{tabular}




\begin{tabular}{|c|c|c|c|c|c|c|c|c|c|}
\hline & & & & $\mathrm{P} 2 \mathrm{Pz}$ & .246 & .277 & .189 & .889 & .383 \\
\hline & & & & N1 Latency & -.057 & .031 & -.353 & -1.846 & .077 \\
\hline & & & & P2 Latency & .038 & .024 & .337 & 1.599 & .122 \\
\hline & & & & (Constant) & -6.133 & 7.011 & & -.875 & .390 \\
\hline \multirow[t]{7}{*}{ S2-P3 } & .076 & .589 & .190 & Late CNV Cz & -.616 & .430 & -.329 & -1.433 & .164 \\
\hline & & & & Early CNV Fz & -.773 & .822 & -.249 & -.940 & .356 \\
\hline & & & & N1 Fz & .292 & .435 & .130 & .671 & .508 \\
\hline & & & & $\mathrm{P} 2 \mathrm{Pz}$ & -.534 & .516 & -.205 & -1.035 & .310 \\
\hline & & & & N1 Latency & -.016 & .057 & -.051 & -.285 & .778 \\
\hline & & & & P2 Latency & .007 & .044 & .317 & 1.615 & .119 \\
\hline & & & & (Constant) & -12.169 & 13.050 & & -.932 & .360 \\
\hline \multirow[t]{7}{*}{ Go-P3 } & .027 & .641 & .270 & Late CNV Cz & -.680 & .337 & -.439 & -2.018 & .054 \\
\hline & & & & Early CNV Fz & -.800 & .645 & -.312 & -1.241 & .226 \\
\hline & & & & N1 Fz & -.360 & .341 & -.193 & -1.054 & .302 \\
\hline & & & & P2 Pz & .816 & .405 & .379 & 2.016 & .055 \\
\hline & & & & N1 Latency & .009 & .045 & .034 & .200 & .843 \\
\hline & & & & P2 Latency & .049 & .034 & .267 & 1.431 & .164 \\
\hline & & & & (Constant) & -11.395 & 10.237 & & -1.113 & .276 \\
\hline \multirow{7}{*}{ NoGo-P3 } & 0001 & 767 & 489 & Late CNV Cz & -1714 & 341 & -914 & -5019 & .001 \\
\hline & & & & Early CNV Fz & 1.276 & .653 & .410 & 1.953 & .062 \\
\hline & & & & N1 Fz & -.073 & .346 & -.032 & -.211 & .834 \\
\hline & & & & $\mathrm{P} 2 \mathrm{Pz}$ & -.011 & .410 & -.004 & -.027 & .979 \\
\hline & & & & N1 Latency & -.093 & .046 & -.288 & -2.039 & .052 \\
\hline & & & & P2 Latency & .094 & .035 & .424 & 2.717 & .012 \\
\hline & & & & (Constant) & -5.894 & 10.367 & & -.569 & .575 \\
\hline
\end{tabular}




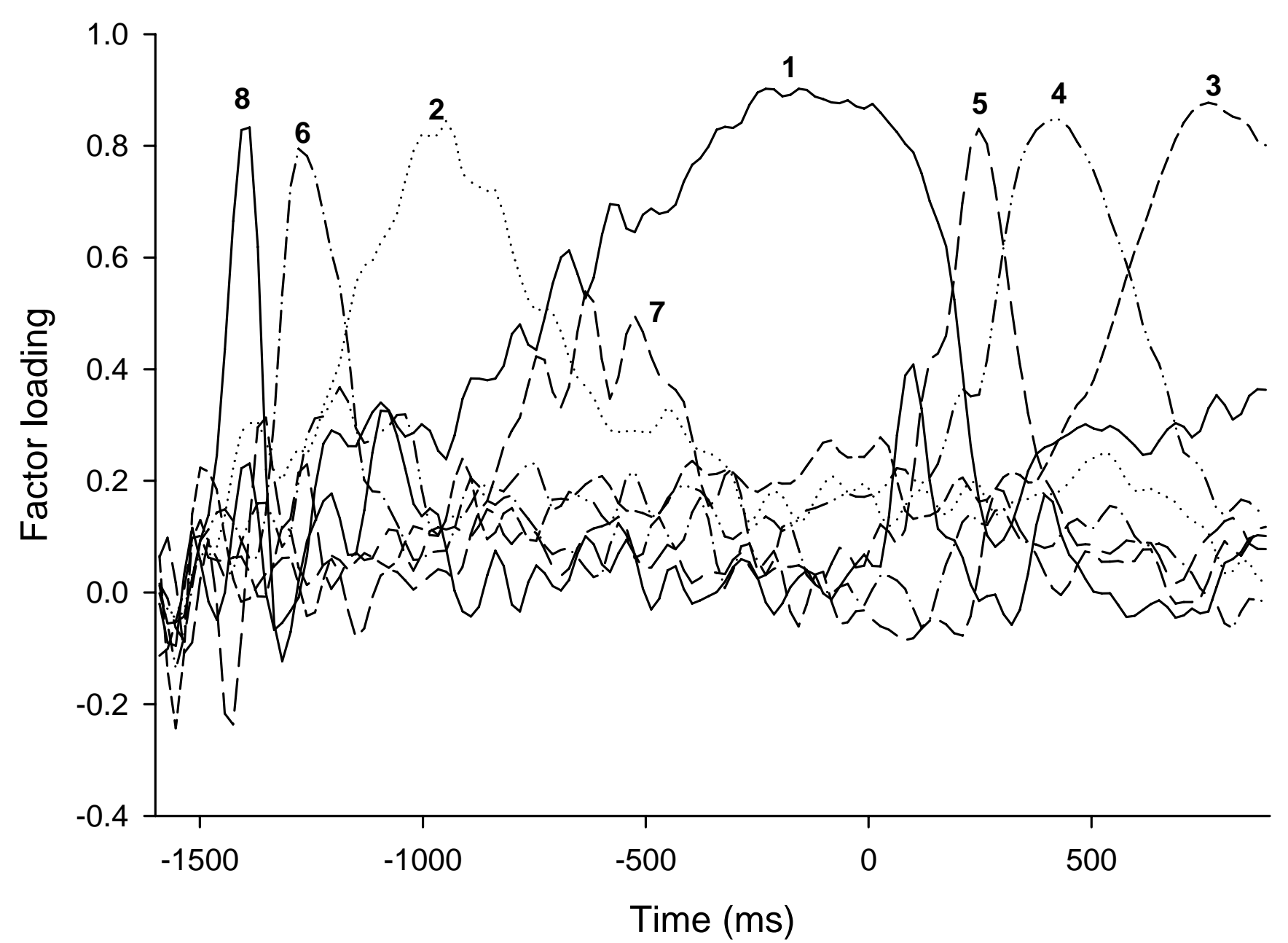

Figure 1. Factor loadings of extracted components over time. Numbers above show the order of extraction. 


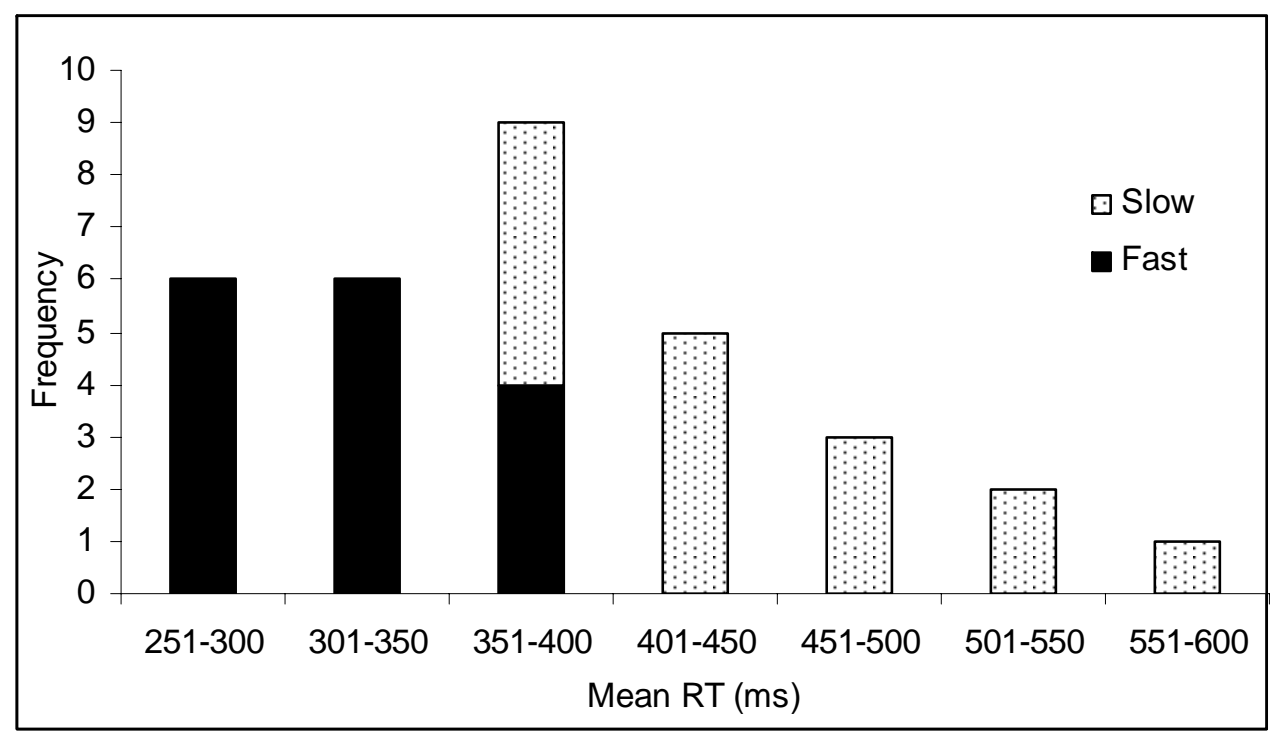

Figure 2. The distribution of mean reaction times for each group. 

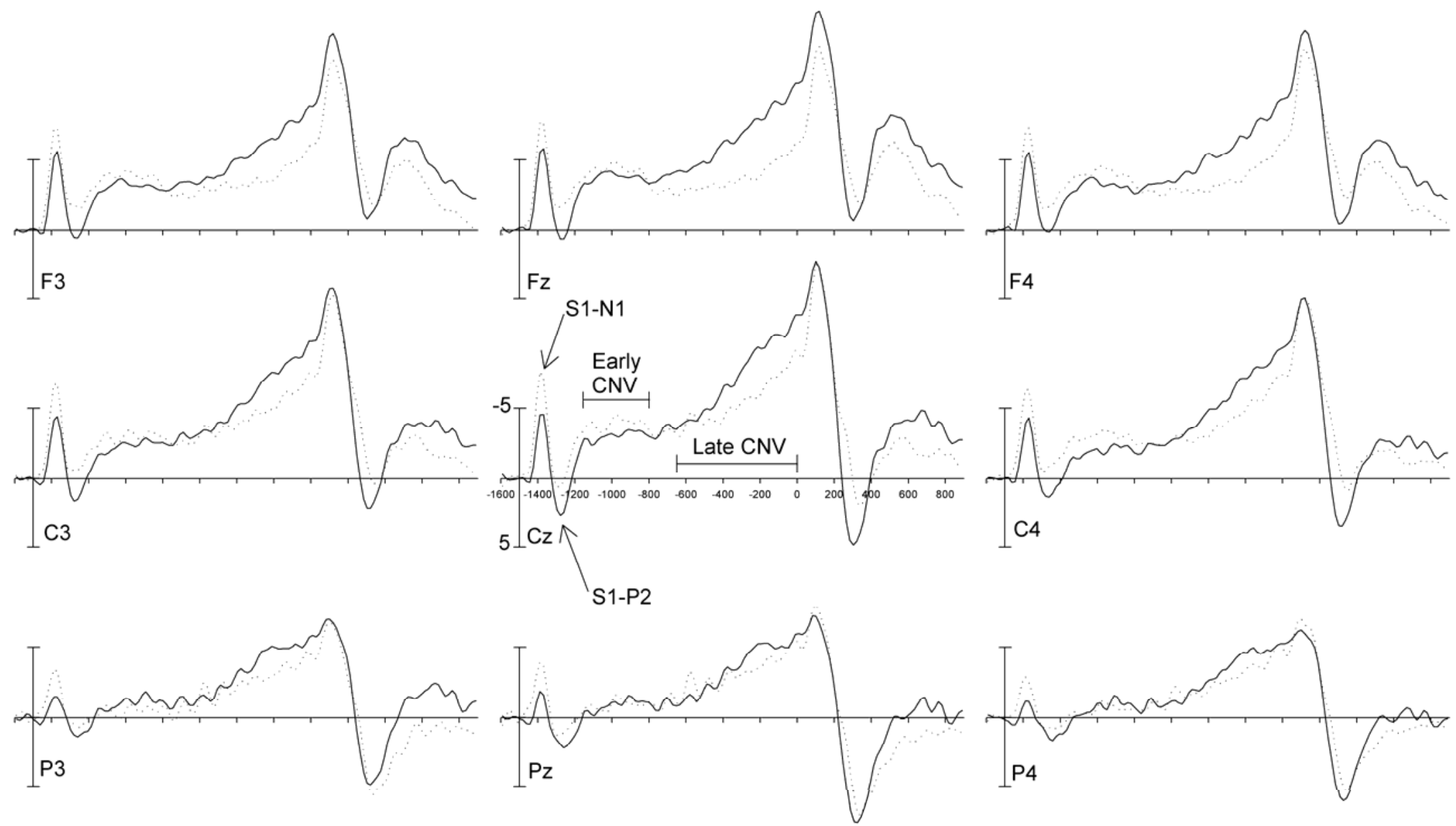

Figure 3. ERP waveforms to Warning stimuli for the Fast group (solid) and Slow group (dotted). Amplitude and time scale marked at Cz. 


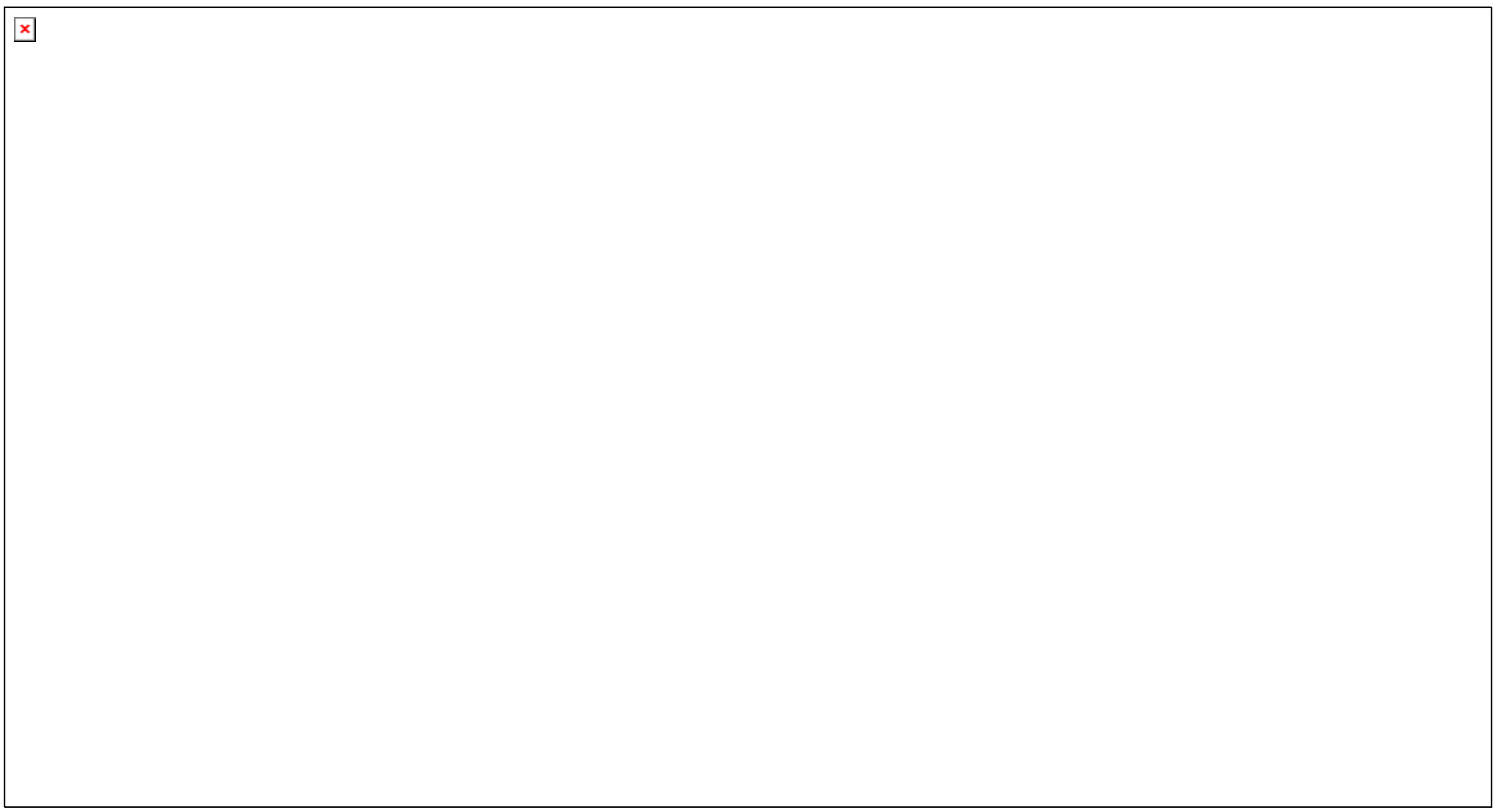

Figure 4a. ERP waveforms for the Fast group to Go (grey) and NoGo stimuli (black). Amplitude and time scale marked at Cz. 


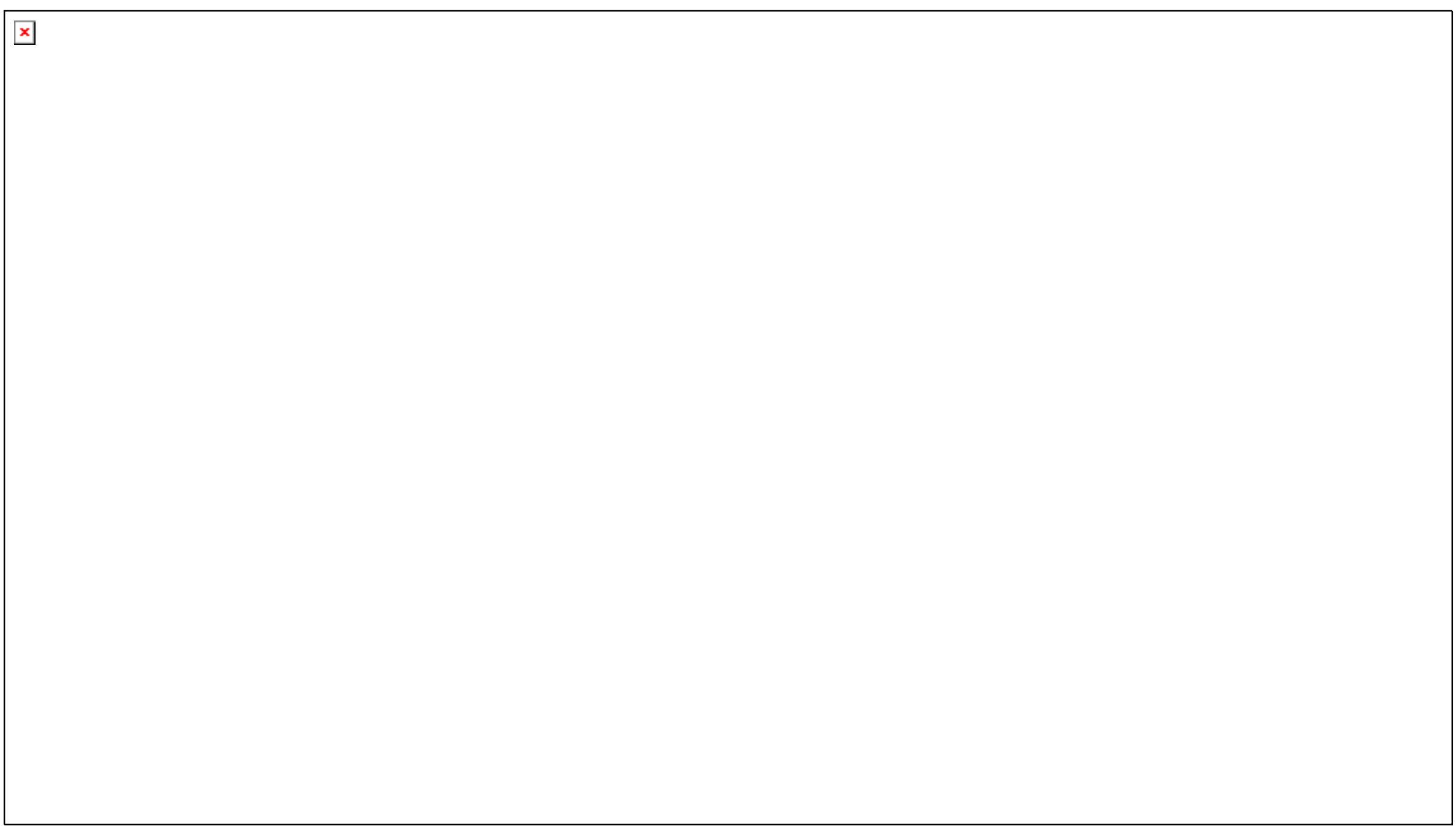

Figure 4b. As for Figure 4a, for the Slow group. 
Footnote 1. In a focused analysis of the $\mathrm{N} 2$ at frontal sites (F3, Fz and F4), the Type main effect was significant $\left(\mathrm{Go}_{\mathrm{o}}=-3.2 \mu \mathrm{V}\right.$, NoGo $\left.=-5.9 \mu \mathrm{V} ; \mathrm{F}=12.7, \mathrm{p}=.001\right)$, and the midline $>$ hemispheres effect was apparent only for NoGo $(-6.2$ vs. $-5.7 \mu \mathrm{V})$ but not Go stimuli $(-3.2$ vs. $-3.3 \mu \mathrm{V} ; \mathrm{F}=5.4, \mathrm{p}=.026)$. Interactions between Type and Group remained nonsignificant, however. 